\title{
An introductory guide to organizational neuroscience
}

\author{
Micah M. Murray ${ }^{1-4} \&$ John Antonakis ${ }^{5}$
}

${ }^{1}$ The LINE (Laboratory for Investigative Neurophysiology), Department of Radiology, University Hospital Center and University of Lausanne, 1011 Lausanne, Switzerland

${ }^{2}$ Department of Ophthalmology, University of Lausanne and Fondation Asile des Aveugles, 1003 Lausanne, Switzerland

${ }^{3}$ The EEG Brain Mapping Core, Center for Biomedical Imaging (CIBM), University Hospital Center and University of Lausanne, 1011 Lausanne, Switzerland

${ }^{4}$ Department of Hearing and Speech Sciences, Vanderbilt University, Nashville, TN 37203-5721, USA

${ }^{5}$ Faculty of Business and Economics, University of Lausanne 


\begin{abstract}
The time is ripe for a renewed and interdisciplinary approach to organizational research that incorporates neuroscientific techniques. Like all methods, they have methodological, analytical, and interpretational limitations; however, the potential gains from using these techniques are far more considerable. We have therefore assembled a succinct yet authoritative collection of articles on the topic of neuroscience in organizational research, to serve as a solid introduction to the methods of neuroscience and what they can accomplish. The special topic is organized into two parts. The first includes a set of accessible reviews of the palette of brain imaging, mapping, and stimulation techniques (fMRI, fNIRS, EEG, MEG, and NIBS) as well as examples of the application of neuroscience methods to various disciplines including economics, marketing, finance, organizational behavior, neuroethology, as well an integrative translational critique on a variety of applications. The second is a collection of articles resulting from a competitive call for submissions that cover various neuroscience topics, but also address important methodological and philosophical issues. The articles lay out a roadmap for the effective integration of neuroscientific methods into organizational research.
\end{abstract}

Keywords: Neuroscience, organizational neuroscience, neuroeconomics, neurofinance, neuromarketing. 
A really funny, though shocking, neuroimaging study was conducted a few years ago. The authors observed the neural reactions of a dead Atlantic salmon that had been placed into an fMRI scanner. The salmon was asked to observe emotionally valenced photographs of humans; incredibly, the researchers discovered activation in a region of the salmon's brain (Bennett, Miller, \& Wolford, 2009)! What happened and why did these researchers undertake the study? Briefly, in attempting to understand brain functioning with neuroimaging, researchers can look at the activation of voxels - tiny representations of cubes of brain tissue - which together map a three-dimensional grid of the brain. Clusters of voxels "lighting up" in a particular region represent the degree of neural activity (typically measured via the blood oxygenation level dependent signal or BOLD signal, see Ogawa, Lee, Kay, \& Tank, 1990) in that region, which is presumably being recruited to undertake a task (Jenkinson \& Chappell, 2018). One problem is that these grids typically have tens of thousands of voxels. With so many voxels (i.e., variables), and a finite sample of entities being studied, conducting multiple statistical tests to detect which voxels light up leads to chance intervening; false positives are bound to be detected, unless appropriate statistical corrections are done for multiple testing (cf. Bennett, Wolford, \& Miller, 2009; Friston, Frith, Liddle, \& Frackowiak, 1991).

As is easy to imagine, the dead salmon study caused quite a stir and circulated prominently in the social media ${ }^{1}$. A natural reaction would be to take conclusions emanating from fMRI studies with heaps of salt. Round about that time, critiques about the benefit of using brain imaging and brain mapping in neuroscientific research came down like a monsoon. Articles warned psychologists about spurious even "voodoo" correlations between brain regions and outcomes (Eklund, Nichols, \& Knutsson, 2016a; Kriegeskorte, Simmons, Bellgowan, \& Baker,

\footnotetext{
${ }^{1}$ See for instance: https://www.altmetric.com/details/411689?src=bookmarklet or https://plu.mx/plum/a/?doi=10.1016/S1053-8119(09)71202-9\&theme=plum-sciencedirect-theme\&hideUsage=true
} 
2009; Vul, Harris, Winkielman, \& Pashler, 2009; Vul \& Pashler, 2012). Books with titles like "Neuromania" warned of how neuro-results are being fetishized (Legrenzi \& Umiltà, 2011). Experiments have also shown that placing irrelevant neuroscience information sways readers into thinking the information therein is more credible; this "allure of neuroscience" bias has been observed in psychology and education (Fernandez-Duque, Evans, Christian, \& Hodges, 2015; Im, Varma, \& Varma, 2017). It is worth noting that criticism of neuroimaging and other non-invasive measures of brain function have been present since the techniques were first developed. For example, the Electroencephalography (EEG) measured by Hans Berger in 1929 was initially considered an artifact. Some considered EEG too slow in its oscillations compared to the action potentials of individual neurons. Other scientists considered EEG to be an artifact of muscle activity. It was only five years later when Adrian and Matthews (1934) replicated Berger's original findings that EEG was more widely accepted as genuine (see Stone \& Hughes, 2013). Of course, neuroscientists worth their salt are cognizant of the various methodological issues that threaten the validity of their data and findings both concerning fMRI studies (see Bednarz \& Kana, 2018; Carp, 2012; Eklund, Nichols, \& Knutsson, 2016b; Poldrack, 2012; Roalf \& Gur, 2017; Soares et al., 2016) as well as EEG studies (Habermann, Weusmann, Stein, \& Koenig, 2018; Lehmann \& Skrandies, 1984; Murray, Brunet, \& Michel, 2008; Picton et al., 2000; Woodman, 2010), to mention two areas. Thus, awareness and training has helped provide guidelines and best practices to ensure replicability, reproducibility, and valid findings that can inform theory and policy. For instance, besides the issue regarding statistical control for type 1 error rates following multiple testing, one of the biggest challenges that faces neuroscience findings concerns what has been dubbed as problem of "reverse inference" (Poldrack, 2006, 2011). That a brain area is activated during a task does not mean that the particular area is responsible for the task; the issue at hand is that any given brain area is typically recruited for 
many different tasks. Thus, neuroscientists have created a database that synthesizes and catalogs research findings so that neuroscientists can compare their results to base rate results from thousands of other studies (Yarkoni, Poldrack, Nichols, D, \& Wager, 2011). ${ }^{2}$

Notwithstanding these critiques, research using neuroscience methods, broadly defined, has made much progress and is used extensively in various social science disciplines; researchers regularly manage to publish this type of research in top journals in marketing (Plassmann, Venkatraman, Huettel, \& Yoon, 2015; Reimann, Castano, Zaichkowsky, \& Bechara, 2012) and psychology (Lumian \& McRae, 2017; Wang, Peng, Chechlacz, Humphreys, \& Sui, 2017), including in applied areas of management (Dulebohn et al., 2016; Molenberghs, Prochilo, Steffens, Zacher, \& Haslam, 2017; Slater, Turner, Evans, \& Jones, 2018; Waldman, Wang, Hannah, \& Balthazard, 2017). Moreover, researchers from economics, finance, and psychology manage to regularly publish in the most prestigious journals like Science, Nature, and the Proceedings of the National Academy of Science (Fliessbach et al., 2007; Hein, Morishima, Leiberg, Sul, \& Fehr, 2016; Knoch, Schneider, Schunk, Hohmann, \& Fehr, 2009; Plassmann, O'Doherty, Shiv, \& Rangel, 2008; Tricomi, Rangel, Camerer, \& O'Doherty, 2010).

Have organizational scientists missed the train? Not really; work is being done, and there have even been two current large-scale literature reviews on the topic (Butler, O'Broin, Lee, \& Senior, 2016; Waldman, Ward, \& Becker, 2017). Still there is some skepticism that neuroscience can add much to our understanding of human behavior in organizations; these issues have been discussed at length in this field (Ashkanasy, Becker, \& Waldman, 2014), though some strong critiques have emerged about the utility and ethicality of neuroscience (Lindebaum, 2016; Lindebaum \& Jordan, 2014). However, there is certainly more weight behind those making prominent calls for neuroscience to gain a firm foothold in the organizational sciences

\footnotetext{
${ }^{2}$ See: http://www.neurosynth.org/
} 
(Antonakis, 2017; Butler, et al., 2016; Lee, Brandes, Chamberlain, \& Senior, 2017; Robertson, Voegtlin, \& Maak, 2017; Waldman, Ward, et al., 2017).

\section{Neuroscience: Some basics and a brief history}

Before introducing the feature topic, we briefly describe a few brain basics ${ }^{3}$ as well as the domains of inquiry that are generally covered by non-invasive neuroscience methods in humans. We would hasten to acknowledge that the field of neuroscience is itself far wider, spanning across species from single-cell organisms through humans and across levels of investigation from molecules to mind. Here are a few key figures about the human brain (see e.g., Kandel, 2013; Raichle \& Gusnard, 2002): It weighs about $1.5 \mathrm{~kg}$ and consists of about 100 billion or so neurons and roughly the same number of glial cells; the number of connections between neurons is estimated at $\sim 100$ trillion or so, and an individual neuron has approximately 10,000 synapses. From an energetic standpoint, the brain is astoundingly efficient—at rest, it runs at about 12-15 watts (standard lightbulbs are 60 watts), which accounts for roughly $20 \%$ of the body's energy consumption. What is more, this energy consumption does not seem to vary with different mental activities (cf. Raichle \& Gusnard, 2002, for discussion). It cannot be understated that the brain is in constant and reciprocal interaction with the rest of the body, including the gut and its hormones (e.g., Rhee, Pothoulakis, \& Mayer, 2009) as well as the neuroendocrine system more generally (Watts, 2015), the heart (Silvani, Calandra-Buonaura, Dampney, \& Cortelli, 2016) along with other muscles and sensory organs.

These interactions are of course paralleled by the brain's regulation of sensation, perception, cognition, and behavior; these functions were attributed to the brain only since the $6^{\text {th }}$ and $5^{\text {th }}$ centuries B.C. in the writings of Alcmaeon of Croton and later in those of Hippocrates in

\footnotetext{
${ }^{3}$ We would direct interested readers to initiatives like the Society for Neuroscience's Brain Facts (http://www.brainfacts.org) where there is a repository of educational videos and podcasts.
} 
the $4^{\text {th }}$ century B.C. However, the role of the brain was debated (e.g., see Glickstein, 2014; Gross, $1999)^{4}$. For example, Aristotle (also active during the $4^{\text {th }}$ century B.C.) considered the brain as a cooling system, whereas the heart was the seat of mental activities. A major contributor to this and similar debates was the absence of rigorous anatomic data; though some insights were nonetheless available based in part on Egyptian embalming procedures, but essentially quiescent until the middle ages and renaissance (Galen, a doctor in the $2^{\text {nd }}$ century A.D. being a notable exception).

In many respects, history repeated itself when it came to functional anatomy and understanding how the brain manifests specific functions. By way of select examples, René Descartes $\left(16^{\text {th }}-17^{\text {th }}\right.$ centuries A.D.) not only conceived of the pineal gland as the seat of thought and the human soul, but also considered the brain to be a largely hydraulic organ; no doubt inspired by the writings of Galen (Glickstein, 2014). This type of reasoning continued to have an influence until the late $18^{\text {th }}$ and early $19^{\text {th }}$ centuries, which marked a conceptual turning point in neuroscience (and most other scientific domains too) due to a confluence of innovations. Whereas history remembers Franz Joseph Gall as "the” champion of phrenology, he also was a pioneer in neuroanatomy (Rawlings \& Rossitch, 1994), whose work was a harbinger of discoveries by individuals such as Ramon y Cajal and Korbinian Brodmann. During the same period, medical advances meant that patients and soldiers would survive for some time after head injury or trauma and that their physicians could describe their functional impairments; for examples, see descriptions of aphasia patients by Paul Broca and Carl Wernicke as well as trauma survivor Phineas Gage (Broca, 1861; Damasio, Grabowski, Frank, Galaburda, \& Damasio, 1994; Gross, 1999, 2012; Harlow, 1848; Wernicke, 1881).

\footnotetext{
${ }^{4}$ There are excellent books on the history of neuroscience. See Glickstein (2014) and Gross( 1999).
} 
During the 1800 s there was a parallel torrent of scientific and technical achievements in domains such as physics (in particular electromagnetism) and engineering that were paving the way for the non-invasive measurement of brain anatomy and function (e.g. individuals such as Alessandro Volta, Georg Simon Ohm, Michael Faraday, James Clerk Maxwell, Heinrich Hertz, and Hermann von Helmholtz) — see Swartz \& Goldensohn (1998). The $20^{\text {th }}$ century and the digital age have likewise ushered in an unprecedented access to the biological underpinnings of behavior. In many respects, this opening was due to tools that allowed for studying the intact brain of living human beings; techniques that are detailed in Part I of this special topic. To give you a sense of how "young" these techniques are, you should bear in mind that electroencephalography (EEG) was introduced in 1924 by Hans Berger (Gloor, 1969). Magnetoencephalography (MEG) was introduced in 1968 by David Cohen (1968). Positron emission tomography (PET) for functional brain imaging was introduced in 1975 by TerPogossian and colleagues (Ter-Pogossian, Phelps, Hoffman, \& Mullani, 1975). Transcranial magnetic stimulation (TMS) was introduced by Antony Barker and colleagues in the mid-1980s (Barker, Jalinous, \& Freeston, 1985) with other varieties of non-invasive brain stimulation (NIBS) techniques developed since then. Most recently, functional magnetic resonance imaging (fMRI) was introduced in 1990 by Ogawa and colleagues(Ogawa, et al., 1990), which was preceded by the development of structural magnetic resonance imaging developed during the mid-1970s by the teams of Lauterbur and Mansfield (Lauterbur, 1973; Mansfield \& Maudsley, 1977). Thus, in the span of less than 100 years a wide variety of techniques have been developed and validated for studying human brain function non-invasively; each with spatial and temporal resolutions that are continuously being refined with advances in their hardware and software (Figure 1). In turn, these advances are promoting greater interpretational power both in terms of correlational versus causal inference and also in terms of being directly coupled to neural activity. 
Although we have, by no means, done justice to the history of (neuro)science here, we hope this overview gives some context to the long history of humanity's interest in understanding itself.

\section{The feature topic}

The backdrop of our introductory remarks provided the impetus for editing a feature topic dedicated to organizational neuroscience. Micah is a trained neuroscientist, and John is specialized in topics germane to organizational behavior and research methods. We came together after having several conversations about a potential collaboration, which led us to edit this feature topic. We saw a need for a succinct yet authoritative collection of articles on the topic, which would serve as solid introduction to the methods of neuroscience and what they can accomplish.

Basically put, our feature topic seeks to answer the following question: What should a typical management researcher need to know to obtain some basic notions of neuroscience and perhaps start a collaboration with a neuroscientist? To answer the question, we decided to lay out in Part I the basic methods of neuroscience (e.g., fMRI, EEG, MEG, NIRS, NIBS, see below for abbreviations), their strengths and weaknesses, how signals can be measured or how they can be interrupted (Chen et al., in press; Chugani, in press) ${ }^{5}$. We then showcase the state-of-the-science in various fields that use neuroscience. We solicited the articles in Part I, using the prominence and knowledge of neuroscience of authors as selection criteria; these articles underwent peerreview. Part II was a competitive call for papers, covering various topics in neuroscience but also methodological and philosophical issues. We summarize the contributions below for both parts:

\section{[Insert Figure 1 about here]}

\footnotetext{
${ }^{5}$ Note, we do not cover Positron Emission Tomography (PET), which in many regards has been replaced by other methods for applied research purposes. However, there are contemporary advances in using PET in combination with other methods (e.g. Chen et al., 2018; Chugani 2018)
} 


\section{Part 1}

This section begins with an article by Loued-Khenissi, Doll, and Preuschoff who provide an overview of Functional Magnetic Resonance Imaging (fMRI). This technique is very popular for gauging brain signals, on the basis of oxygenation of brain regions (using magnetic properties of hemoglobin), and for mapping out brain regions and their functions in three dimensional space. Loued-Kenissi and colleagues explain how fMRI works, what it is useful for, how studies using fMRI are usually designed, and how data are analyzed. They discuss issues of causality, the strengths and weakness of the method (including the problem of signal-detection time lag), and also cover how fMRI can be combined with other neuroscience signal detection methods.

Quaresima and Ferrari follow by presenting a relatively newer technique to measure brain signals, Functional Near-Infrared Spectroscopy (fNIRS). This approach is similar to fMRI—in terms of gauging oxygenation of brain regions — but using near infrared (NIR) light, which is projected through the head. The approach infers the use of a brain region from the light absorption properties of hemoglobin. The authors also discuss what advantages and disadvantage the method brings; for instance, although it has a smaller penetration depth compared to fMRI, fNIRS has several advantages including cost and portability.

Next, Tivadar and Murray provide a primer on electroencephalography (EEG) and eventrelated potentials (ERPs). EEG is perhaps the oldest of the brain mapping/imaging methods dating back nearly a century. The authors provide an accessible description of what EEG/ERPs measures and how as well as how the data are analyzed. They discuss how some varieties of analyses are ambiguous because of misunderstandings of the neurobiological and biophysical bases of the signals. They also discuss alternative approaches that are more robust and informative. They close by situating EEG/ERPs alongside the interests of organizational researchers and discuss in a balanced way the benefits and limitations of the technique. 
Ahlfors and Mody present Magnetoencephalography (MEG). Like its close cousin EEG, MEG instantaneously measures electrical signals from the brain using sensors, fitting over the head like a giant beauty salon hair dryer (instead of using EEG-type scalp electrodes integrated in a cap or net). As with the previous articles, the authors discuss how MEG signals are detected, the strengths and weaknesses of the method, how MEG can be integrated in a multimodal framework; they also provide examples of the use of the method.

Instead of measuring its signals, how about knocking out the brain's ability to perform a task? Veniero, Strüber, Thut, and Herrmann present a rather useful method to study the brain, which does just that. Noninvasive brain stimulation (NIBS), which includes transcranial magnetic stimulation (TMS) and transcranial electric stimulation (tES), interfere with brain activity and allows researchers the possibility to answer causal question. These methods are cheap and quite easy to use. The authors discuss their utility and safety, and provide examples of research questions that can be answered with these tools.

The next five papers are less technical and more applied in nature. The first four showcase how social science disciplines, including economics (Konovalo and Krajbich), marketing (Karmarkar and Plassmann), finance (Miendlarzewska, Kometer, \& Preuschoff), and organizational behavior (Waldman, Wang, and Fenters) have benefited from using neuroscientific methods. Because researchers from the disciplines of economics, marketing, and finance were relatively early adopters of neuroscientific methods, organizational scientists have much to learn from these articles particularly with respect to expectation they should have regarding what these methods can offer them, the kinds of phenomena that can have studied, and which neuroscience methods have been proven to be useful for organizational and economicrelated contexts. The fourth article by Menieur, a primatologist, looks at neuroscience from a 
neuroethology point of view, and in particular, how studying primates can help explain the origins of some human behaviors.

The final article in Part 1 is by Spence, who has much experience in writing about technical issues in non-technical ways (e.g., see Spence, 2017; Spence \& Piqueras-Fiszman, 2014). He explores the limits of neuroscience designs and what they can accomplish over traditional behavioral methods in business settings.

\section{Part 2}

This part of the feature topic includes a diverse set of papers. First, Bagozzi and Lee discuss philosophical issues in neuroscience, focusing specifically on consciousness. This article covers

much territory and focuses essentially on what is the meaning of brain activity and to what extent one can infer consciousness from biological underpinnings. They point to the limits of current neuroscience methods and suggest that new methods must be discovered to the solve mind-brain conundrum.

Next, Braeutigam, Lee, and Senior follow with an article on endogenous brain states; the brain shows constant activity even in its resting state. They provide several pointers regarding what types of questions can be studied in the organizational sciences, specifically in predicting the preferences, choices, or even vocations or different types of individuals from their endogenous brain states.

The next two articles take a rather different tack to all others in this feature topic: They do not focus on the brain per se, but on different aspects of neurological functioning. Massaro and Pecchia discuss heart rate variability, and how doing so can be used to make inferences about the autonomic nervous system. This area of research and a related area-which is the focus of the article by Christopoulos, Uy, and Yap who discuss skin conductance response - are curiously absent in the organizational sciences. The authors discuss how autonomic signals from the heart 
or skin can be processed and analyzed, and what types of phenomena can be studied using these methods, as applied to organizational science.

Finally, Jack, Rochford, Friedman, Passarelli, and Boyatzis, review the various challenges and pitfalls that neuroscience faces. They discuss the different approaches to measure brain signals or to perturb them, as well as other workhorses of neuroscience (e.g., lesion studies), and showcase their utility for organizational scholars. They sprinkle their article with methodological nuggets and critically assess how neuroscience methods can be used in a robust manner.

\section{Conclusion}

We hope that organizational scholars find the collection of articles in this feature topic interesting and useful. Neuroscience in the general sense of the word including the brain and the neuroendocrinological system have much to offer; in particular, such data are free from the "cheap talk" and social desirability that plague self-reports and questionnaires (Antonakis, 2017; Podsakoff \& Organ, 1986); they are directly observable, objective, and can be measured in a relatively inexpensive manner. There has been much hype surrounding neuroscience in the past and expectations about what we could learn from it were set very high; at the same time, many scholars may not have understood what neuroscience was all about. Perhaps the hype, the expectations, and the unfamiliarity with the methods made scholars from the organizational sciences cautious about embracing neuroscience. Neuroscience has come a long way and organizational scholars should embrace it. Results from neuroscience studies can help answer many questions and inform both basic and applied research. We hope we have given organizational scholars some fish for thought. 
Figure 1: The operational space of non-invasive neuroscience methods

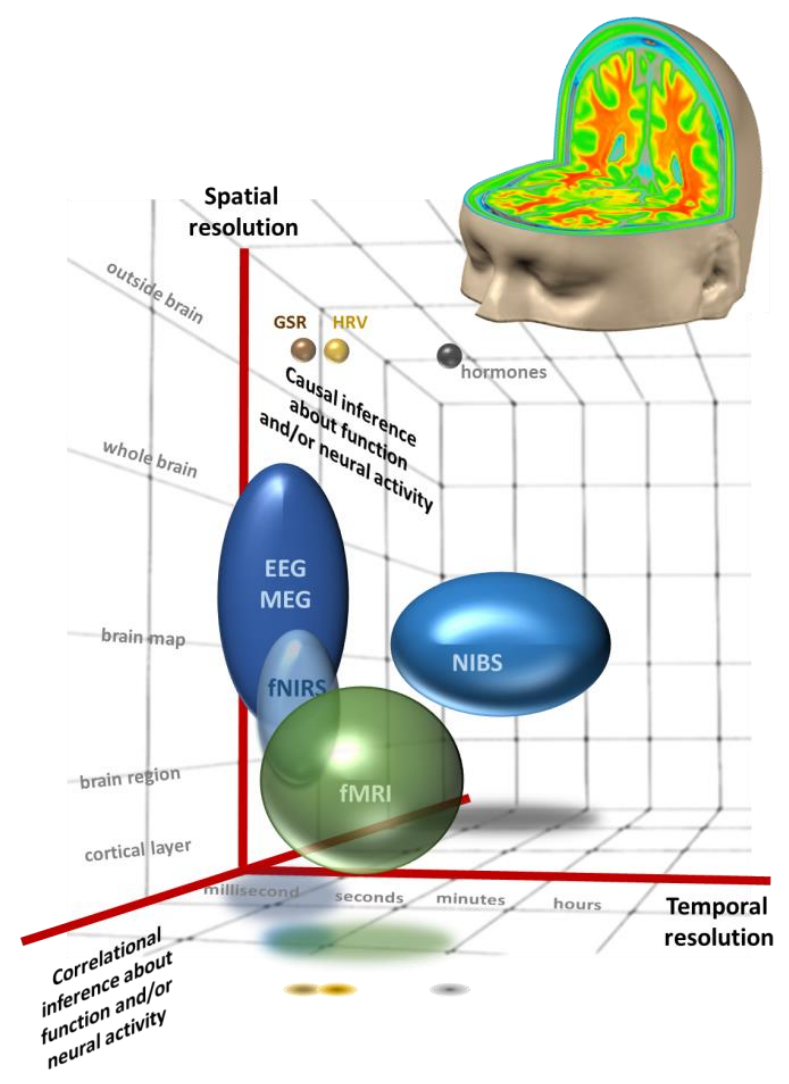

\section{Figure Caption}

Here we schematize the relative temporal and spatial resolution of commonly used methods, as well as their capacity to provide causal versus correlational inference regarding function and/or neural activity. The size of the sphere/oval convey the range of resolution along a given axis. For example, EEG and MEG can have fine-grained temporal resolution (<millisecond) and variable spatial resolution depending on the acquisition and analysis parameters. They are both direct measures of neural activity, but can only provide correlational inference regarding brain function (at least when used in isolation). The measurement of hormones, such as testosterone, has a more restricted range (and hence is schematized here by a small sphere), has a slow temporal resolution, is a measurement outside of the brain, and thus provides exclusively correlational inference about brain function and neural activity. Acronyms: EEG = electroencephalography, fMRI = functional magnetic resonance imaging, fNIRS = functional near infrared spectroscopy, GSR = Galvanic skin response, $\mathrm{HVR}=$ heart rate variability, $\mathrm{MEG}=$ magnetoencephalography, NIBS = non-invasive brain stimulation). This schema has been inspired by similar images in Churchland and Sejnowski (1988), Churchland and Sejnowski (1988) and Walsh and Cowey (2000). 


\section{References}

Antonakis, J. (2017). On doing better science: From thrill of discovery to policy implications. The Leadership Quarterly, 28(1), 5-21.

Ashkanasy, N. M., Becker, W. J., \& Waldman, D. A. (2014). Neuroscience and organizational behavior: Avoiding both neuro-euphoria and neuro-phobia. Journal of Organizational Behavior, http://dx.doi.org/10.1002/job.1952.

Barker, A. T., Jalinous, R., \& Freeston, I. L. (1985). Non-invasive magnetic stimulation of human motor cortex. The Lancet, 325(8437), 1106-1107.

Bednarz, H. M., \& Kana, R. K. (2018). Advances, challenges, and promises in pediatric neuroimaging of neurodevelopmental disorders. Neuroscience and Biobehavioral Reviews, 90, 50-69.

Bennett, C. M., Miller, M. B., \& Wolford, G. L. (2009). Neural correlates of interspecies perspective taking in the post-mortem Atlantic Salmon: an argument for multiple comparisons correction. Neuroimage, 47, S125.

Bennett, C. M., Wolford, G. L., \& Miller, M. B. (2009). The principled control of false positives in neuroimaging. Social Cognitive and Affective Neuroscience, 4(4), 417-422.

Broca, P. (1861). Perte de la parole, ramollissement chronique et destruction partielle du lobe antérieur gauche du cerveau. Bull Soc Anthropol, 2(1), 235-238.

Butler, M. J. R., O'Broin, H. L. R., Lee, N., \& Senior, C. (2016). How Organizational Cognitive Neuroscience Can Deepen Understanding of Managerial Decision-making: A Review of the Recent Literature and Future Directions. International Journal of Management Reviews, 18(4), 542-559.

Carp, J. (2012). The secret lives of experiments: Methods reporting in the fMRI literature. Neuroimage, 63(1), 289-300.

Chen, Z., Jamadar, S. D., Li, S., Sforazzini, F., Baran, J., Ferris, N., et al. (in press). From simultaneous to synergistic MR-PET brain imaging: A review of hybrid MR-PET imaging methodologies. Human Brain Mapping, doi:10.1002/hbm.24314.

Chugani, H. T. (in press). Imaging Brain Metabolism in the Newborn. Journal of Child Neurology, https://doi.org/10.1177/0883073818792308.

Churchland, P. S., \& Sejnowski, T. J. (1988). Perspectives on cognitive neuroscience. Science, 242(4879), 741-745.

Cohen, D. (1968). Magnetoencephalography: evidence of magnetic fields produced by alpharhythm currents. Science, 161(3843), 784-786.

Damasio, H., Grabowski, T., Frank, R., Galaburda, A. M., \& Damasio, A. R. (1994). The return of Gage, Phineas: Clues about the brani from the skull of a famous patient. Science, 264(5162), 1102-1105.

Dulebohn, J. H., Davison, R. B., Lee, S. A., Conlon, D. E., McNamara, G., \& Sarinopoulos, I. C. (2016). Gender Differences in Justice Evaluations: Evidence From fMRI. [Article]. Journal of Applied Psychology, 101(2), 151-170.

Eklund, A., Nichols, T. E., \& Knutsson, H. (2016a). Cluster failure: why fMRI inferences for spatial extent have inflated false-positive rates. Proceedings of the National Academy of Sciences, 113(28), 7900-7905.

Eklund, A., Nichols, T. E., \& Knutsson, H. (2016b). Cluster failure: why fMRI inferences for spatial extent have inflated false-positive rates. Proceedings of the National Academy of Sciences, 201602413. 
Fernandez-Duque, D., Evans, J., Christian, C., \& Hodges, S. D. (2015). Superfluous Neuroscience Information Makes Explanations of Psychological Phenomena More Appealing. Journal of Cognitive Neuroscience, 27(5), 926-944.

Fliessbach, K., Weber, B., Trautner, P., Dohmen, T., Sunde, U., Elger, C. E., et al. (2007). Social comparison affects reward-related brain activity in the human ventral striatum. Science, 318(5854), 1305-1308.

Friston, K. J., Frith, C., Liddle, P., \& Frackowiak, R. (1991). Comparing functional (PET) images: the assessment of significant change. Journal of Cerebral Blood Flow \& Metabolism, 11(4), 690-699.

Glickstein, M. (2014). Neuroscience: a historical introduction: MIT Press.

Gloor, P. (1969). "Hans Berger and the discovery of the electroencephalogram". Electroencephalography and Clinical Neurophysiology, Suppl 28, 1-36.

Gross, C. G. (1999). Brain, vision, memory: Tales in the history of neuroscience: MIT Press.

Gross, C. G. (2012). A hole in the head: more tales in the history of neuroscience: MIT Press.

Habermann, M., Weusmann, D., Stein, M., \& Koenig, T. (2018). A Student's Guide to Randomization Statistics for Multichannel Event-Related Potentials Using Ragu. Frontiers in Neuroscience, 12.

Harlow, J. M. (1848). Passage of an iron rod through the head. The Boston Medical and Surgical Journal (1828-1851), 39(20), 0_1.

Hein, G., Morishima, Y., Leiberg, S., Sul, S., \& Fehr, E. (2016). The brain's functional network architecture reveals human motives. Science, 351(6277), 1074-1078.

Im, S. h., Varma, K., \& Varma, S. (2017). Extending the seductive allure of neuroscience explanations effect to popular articles about educational topics. British Journal of Educational Psychology, 87(4), 518-534.

Jenkinson, M., \& Chappell, M. (2018). Introduction to Neuroimaging Analysis: Oxford University Press.

Kandel, E. R. (2013). Principles of neural science (5th ed.). New York: McGraw-Hill.

Knoch, D., Schneider, F., Schunk, D., Hohmann, M., \& Fehr, E. (2009). Disrupting the prefrontal cortex diminishes the human ability to build a good reputation. Proceedings of the National Academy of Sciences of the United States of America, 106(49), 20895-20899.

Kriegeskorte, N., Simmons, W. K., Bellgowan, P. S., \& Baker, C. I. (2009). Circular analysis in systems neuroscience: the dangers of double dipping. Nature neuroscience, 12(5), 535540.

Lauterbur, P. C. (1973). Image Formation by Induced Local Interactions: Examples Employing Nuclear Magnetic Resonance. Nature, 242, 190.

Lee, N., Brandes, L., Chamberlain, L., \& Senior, C. (2017). This is your brain on neuromarketing: reflections on a decade of research. Journal of Marketing Management, 33(11-12), 878-892.

Legrenzi, P., \& Umiltà, C. (2011). Neuromania: On the limits of brain science: Oxford University Press.

Lehmann, D., \& Skrandies, W. (1984). Spatial analysis of evoked potentials in man--a review. Progress in neurobiology, 23(3), 227-250.

Lindebaum, D. (2016). Critical Essay: Building new management theories on sound data? The case of neuroscience. Human Relations, 69(3), 537-550.

Lindebaum, D., \& Jordan, P. J. (2014). A critique on neuroscientific methodologies in organizational behavior and management studies. Journal of Organizational Behavior, 35(7), 898-908. 
Lumian, D. S., \& McRae, K. (2017). Preregistered Replication of "Affective Flexibility: Evaluative Processing Goals Shape Amygdala Activity". Psychological Science, 28(9), 1193-1200.

Mansfield, P., \& Maudsley, A. (1977). Medical imaging by NMR. The British journal of radiology, 50(591), 188-194.

Molenberghs, P., Prochilo, G., Steffens, N. K., Zacher, H., \& Haslam, S. A. (2017). The Neuroscience of Inspirational Leadership: The Importance of Collective-Oriented Language and Shared Group Membership. [Article]. Journal of Management, 43(7), 2168-2194.

Murray, M. M., Brunet, D., \& Michel, C. M. (2008). Topographic ERP analyses: a step-by-step tutorial review. Brain topography, 20(4), 249-264.

Ogawa, S., Lee, T.-M., Kay, A. R., \& Tank, D. W. (1990). Brain magnetic resonance imaging with contrast dependent on blood oxygenation. Proceedings of the National Academy of Sciences, 87(24), 9868-9872.

Picton, T. W., Bentin, S., Berg, P., Donchin, E., Hillyard, S. A., Johnson, R., et al. (2000). Guidelines for using human event-related potentials to study cognition: recording standards and publication criteria. Psychophysiology, 37(2), 127-152.

Plassmann, H., O'Doherty, J., Shiv, B., \& Rangel, A. (2008). Marketing actions can modulate neural representations of experienced pleasantness. Proceedings of the National Academy of Sciences of the United States of America, 105(3), 1050-1054.

Plassmann, H., Venkatraman, V., Huettel, S., \& Yoon, C. (2015). Consumer Neuroscience: Applications, Challenges, and Possible Solutions. Journal of Marketing Research, 52(4), 427-435.

Podsakoff, P. M., \& Organ, D. W. (1986). Self-reports in organizational research: Problems and prospects. Journal of Management, 12(4), 531-544.

Poldrack, R. A. (2006). Can cognitive processes be inferred from neuroimaging data? Trends in Cognitive Sciences, 10(2), 59-63.

Poldrack, R. A. (2011). Inferring Mental States from Neuroimaging Data: From Reverse Inference to Large-Scale Decoding. Neuron, 72(5), 692-697.

Poldrack, R. A. (2012). The future of fMRI in cognitive neuroscience. Neuroimage, 62(2), 12161220.

Raichle, M. E., \& Gusnard, D. A. (2002). Appraising the brain's energy budget. Proceedings of the National Academy of Sciences, 99(16), 10237-10239.

Rawlings, C. E., \& Rossitch, E. (1994). Franz Josef Gall and his contribution to neuroanatomy with emphasis on the brain stem. Surgical neurology, 42(3), 272-275.

Reimann, M., Castano, R., Zaichkowsky, J., \& Bechara, A. (2012). How we relate to brands: Psychological and neurophysiological insights into consumer-brand relationships. Journal of Consumer Psychology, 22(1), 128-142.

Rhee, S. H., Pothoulakis, C., \& Mayer, E. A. (2009). Principles and clinical implications of the brain-gut-enteric microbiota axis. [Review Article]. Nature Reviews Gastroenterology \&Amp; Hepatology, 6, 306.

Roalf, D. R., \& Gur, R. C. (2017). Functional Brain Imaging in Neuropsychology Over the Past 25 Years. Neuropsychology, 31(8), 954-971.

Robertson, D. C., Voegtlin, C., \& Maak, T. (2017). Business Ethics: The Promise of Neuroscience. Journal of Business Ethics, 144(4), 679-697. 
Silvani, A., Calandra-Buonaura, G., Dampney, R. A., \& Cortelli, P. (2016). Brain-heart interactions: physiology and clinical implications. Phil. Trans. R. Soc. A, 374(2067), 20150181.

Slater, M. J., Turner, M. J., Evans, A. L., \& Jones, M. V. (2018). Capturing hearts and minds: The influence of relational identification with the leader on followers' mobilization and cardiovascular reactivity. Leadership Quarterly, 29(3), 379-388.

Soares, J. M., Magalhaes, R., Moreira, P. S., Sousa, A., Ganz, E., Sampaio, A., et al. (2016). A Hitchhiker's Guide to Functional Magnetic Resonance Imaging. [Review]. Frontiers in Neuroscience, 10.

Spence, C. (2017). Gastrophysics: the new science of eating: Penguin UK.

Spence, C., \& Piqueras-Fiszman, B. (2014). The perfect meal: the multisensory science of food and dining: John Wiley \& Sons.

Stone, J. L., \& Hughes, J. R. (2013). Early History of Electroencephalography and Establishment of the American Clinical Neurophysiology Society. Journal of Clinical Neurophysiology, $30(1), 28-44$.

Swartz, B., \& Goldensohn, E. (1998). Timeline of the history of EEG and associated fields. Electroencephalography and clinical Neurophysiology, 106(2), 173-176.

Ter-Pogossian, M. M., Phelps, M. E., Hoffman, E. J., \& Mullani, N. A. (1975). A positronemission transaxial tomograph for nuclear imaging (PETT). Radiology, 114(1), 89-98.

Tricomi, E., Rangel, A., Camerer, C. F., \& O'Doherty, J. P. (2010). Neural evidence for inequality-averse social preferences. Nature, 463(7284), 1089-U1109.

Vul, E., Harris, C., Winkielman, P., \& Pashler, H. (2009). Puzzlingly High Correlations in fMRI Studies of Emotion, Personality, and Social Cognition. Perspectives on Psychological Science, 4(3), 274-290.

Vul, E., \& Pashler, H. (2012). Voodoo and circularity errors. Neuroimage, 62(2), 945-948.

Waldman, D. A., Wang, D. N., Hannah, S. T., \& Balthazard, P. A. (2017). A neurological and ideological perspective of ethical leadership. Academy of Management Journal, 60(4), 1285-1306.

Waldman, D. A., Ward, M. K., \& Becker, W. J. (2017). Neuroscience in Organizational Behavior. Annual Review of Organizational Psychology and Organizational Behavior, 4(1), 425-444.

Walsh, V., \& Cowey, A. (2000). Transcranial magnetic stimulation and cognitive neuroscience. Nature Reviews Neuroscience, 1(1), 73-80.

Wang, F., Peng, K. P., Chechlacz, M., Humphreys, G. W., \& Sui, J. (2017). The Neural Basis of Independence Versus Interdependence Orientations: A Voxel-Based Morphometric Analysis of Brain Volume. Psychological Science, 28(4), 519-529.

Watts, A. G. (2015). The structure of the neuroendocrine hypothalamus: the neuroanatomical legacy of Geoffrey Harris. Journal of Endocrinology, JOE-15-0157.

Wernicke, C. (1881). Lehrbuch der gehirnkrankheiten für aerzte und studirende (Vol. 2): Fischer.

Woodman, G. F. (2010). A brief introduction to the use of event-related potentials in studies of perception and attention. Attention, Perception, \& Psychophysics, 72(8), 2031-2046.

Yarkoni, T., Poldrack, R. A., Nichols, T., D, V. E., \& Wager, T. D. (2011). NeuroSynth: a new platform for large-scale automated synthesis of human functional neuroimaging data. Front. Neuroinform. Conference Abstract: 4th INCF Congress of Neuroinformatics. doi:10.3389/conf.fninf.2011.08.00058. 